\section{Drug Shortages in Health Care Institutions: Perspectives in Early 2012}

In news articles published in the Canadian Medical Association Journal in 2010 and 2011, Eggertson highlighted the problem of drug shortages in Canada and described initiatives of the Canadian Pharmacists Association, hospital pharmacists, and drug manufacturers to address the problem. ${ }^{1,2}$

Many stakeholders have underscored the importance of the drug shortage problem and its risks, but few quantitative data have been published., ${ }^{3,4}$ A few regulatory agencies (e.g., the US Food and Drug Administration ${ }^{5}$ and the Agence française de sécurité sanitaire des produits de santé in France ${ }^{6}$ ) and a few professional organizations and associations (e.g., the US Institute for Safe Medication Practices, ${ }^{7}$ the American Society of HealthSystem Pharmacists, ${ }^{8}$ and the Canadian Pharmacists Association $^{9}$ ) have published online guidelines and lists of product shortages to make it easier to manage these events.

In Canada, the Pharmacy Practice Research Unit of the Centre hospitalier universitaire Sainte-Justine launched an openaccess website in February 2011 that provides a progress report on all drug shortages in health care institutions (see www.fridaypm.ca [English] and www.vendredipm.ca [French]). Many of these shortages also affect outpatients using oral formulations. Initially, the website was being updated every 2 weeks by our research team using a list of drug shortages provided by the wholesaler McKesson Canada, under contract to SigmaSanté (the group purchasing agent for hospital group purchases in the Montréal and Laval areas and the Eastern Townships of Quebec) and through self-reporting by hospitals. Starting in January 2012, the website was being updated directly by the manufacturers on a voluntary pilot basis; doing so became mandatory on April 1, 2012, according to contractual terms and conditions with SigmaSanté. This real-time updating should make it possible to immediately display progress reports for all of the stakeholders.

Our research unit has been interested in drug shortages for more than a year. In a recently published retrospective study ${ }^{10}$ we compiled a list of all the drug shortages experienced by health care institutions in the Montréal and Laval areas and the Eastern Townships from January 2006 to August 2010. Since then, we have gathered data on shortages from August 30, 2010, to August 23, 2011. Our latest data indicate that there were a total of 429 drug shortages in this 12-month period in 2010-2011; the corresponding numbers of drug shortages were 493 in calendar year 2006, 400 in 2007, 442 in 2008, 680 in 2009, and 385 in the first 8 months of 2010 . The average duration $( \pm$ standard deviation) of the drug shortages has remained similar, with $108 \pm 130$ days (range 5-1623 days) over the period 2006-2010 and $103 \pm 85$ days (range 8-363) for the 12-month period in 2010-2011.
The number of manufacturers involved in drug shortages has declined (41 in 2010-2011 versus 70 over the period 2006-2010), undoubtedly because of mergers and integration or closing of certain drug manufacturers. Most of the documented shortages came from generic drug manufacturers, and their relative ranking has remained similar. For the period 2006-2010, the ranking for generic manufacturers, in decreasing order, was as follows: Apotex, accounting for 19\% of total drug shortages; Pharmascience, 14\%; Novopharm (now Teva), 12\%; Sandoz, 10\%; Hospira, 6\%; Teva, 4\%; Baxter, 3\%; Ratiopharm, 3\%; Omega, 2\%; and Taro, 2\%. For the 12-month period in 2010 2011, the ranking was Teva, 23\%; Apotex, 16\%; Pharmascience, 12\%; Hospira, 7\%; Sandoz, 7\%; Baxter, 5\%; AA Pharma (created from the resale of certain licences held by Apotex), 3\%; Schering, 3\%; Abbott, 3\%; and Merck Canada, 2\%.

In both periods, most therapeutic classes were involved in drug shortages. For the 12-month study period in 2010-2011, drug classes involved in shortages were, in decreasing order, central nervous system agents (AHFS drug classification 28:00), accounting for $24 \%$ of products; anti-infective agents (08:00), 16\%; cardiovascular drugs (24:00), 10\%; antineoplastic drugs (10:00), 7\%; electrolytic, caloric, and water balance agents (40:00), 7\%; gastrointestinal drugs (56:00), 7\%; hormones and synthetic substitutes (68:00), 7\%; and all other classes, $22 \%$.

Our work underlines the need to document the quantities and impacts of drug shortages. The actual status of drug shortages by product should be updated daily by manufacturers and published online, as this information is essential to efficiently manage drug shortages and reduce delays in the availability of relevant information to all stakeholders. The website set up by our team and the contractual framework to be used by our group purchasing organization may be of assistance in obtaining manufacturers' data about shortages. Finally, there is no doubt that collaboration among patients, physicians, and pharmacists will be required to react proactively in the event of drug shortages.

References

1. Eggertson L. Continuing drug shortages affect North American patients. CMAJ 2010;182(18):E811-E812.

2. Eggertson L. Drug shortage registry under discussion. CMAJ 2011; 183(10):E637-E638.

3. Traynor K. Drug shortages mount in 2010. Am J Health Syst Pharm 2010; 67(18):1492-1494.

4. Canadian drug shortages survey: final report. Ottawa (ON): Canadian Pharmacists Association; 2010 Dec [cited 2012 Mar 21]. Available from: www.pharmacists.ca/cpha-ca/assets/File/cpha-on-the-issues/DrugShortages Report.pdf

5. Drug shortages. Silver Spring (MD): US Food and Drug Administration; [cited 2011 Jun 14]. Available from: www.fda.gov/Drugs/DrugSafety/ DrugShortages/default.htm

6. Formulaire de déclaration de rupture de stocks à l'intention des laboratoires. Saint Denis (France): Agence française de sécurité sanitaire des produits de santé; 2008 [cited 2011 Jun 14]. Available from: www.afssaps.fr/ Infos-de-securite/Ruptures-de-stock-et-arrets-de-commercialisation-desmedicaments 
7. Drug shortages: national survey reveals high level of frustration, low level of safety. Horsham (PA): Institute for Safe Medication Practices; 2010 Sep 23 [cited 2011 Jun 14]. Available from: www.ismp.org/Newsletters/ acutecare/articles/20100923.asp

8. ASHP Expert Panel on Drug Product Shortages, Fox ER, Birt A, James KB, Kokko H, Salverson S, Soflin DL. ASHP guidelines on managing drug product shortages in hospitals and health systems. Am J Health Syst Pharm 2009;66(15):1399-1406.

9. Drug shortages: a guide for assessment and patient management. Ottawa (ON): Canadian Pharmacists Association; 2010 [cited 2012 Mar 21]. Available from: www.pharmacists.ca/cpha-ca/assets/File/cpha-on-the-issues/ DrugShortagesGuide.pdf

10. Bussières JF, Chiveri A, Lebel D. Perspective sur les ruptures d'approvisionnement de médicaments en établissement de santé de 2006 à 2010. Can J Hosp Pharm 2011;64(6):426-435.

\section{Géraldine Ottino}

Research Assistant

Denis Lebel, BPharm, MSc, FCSHP

Assistant Director

Jean-François Bussières, BPharm, MSC, FCSHP

Director

Pharmacy Practice Research Unit

CHU Sainte-Justine

Montréal, Quebec

Géraldine Ottino is also a DPharm student at Université Claude Bernard Lyon 1, Villeurbanne, France. Denis Lebel is also Assistant Director, Pharmaceutical Care, Teaching, and Research, with the Pharmacy Department of CHU Sainte-Justine. Jean-François Bussières is also Director of the Pharmacy Department of CHU Sainte-Justine and Professor with the Faculty of Pharmacy, Université de Montréal.

\section{Research Grants from the CSHP Research and Education Foundation}

The recent article by Zed and others ${ }^{1}$ highlights the unique and important role that the Research and Education Foundation of the Canadian Society of Hospital Pharmacists (the CSHP Foundation) has played in advancing research among hospital pharmacists in Canada. Significant findings of the survey included the high number of publications and presentations of research results and the value that CSHP members placed on having their own funding body for hospital pharmacy research. The Board of the CSHP Foundation is pleased that the survey demonstrated the high quality of research performed and the need for this type of funding. We wholeheartedly agree with the investigators' sentiment that the CSHP Foundation should increase the award amounts and fund more projects.

The survey respondents expressed the belief that the research conducted was clinically important. We concur with this assessment and would further suggest that CSHP Foundation research grants have many tangible and intangible benefits, including benefits to patient care, to pharmacists and other health provider colleagues, and to the pharmacy profession itself. The CSHP Foundation recently conducted its own survey of grant recipients to elicit these types of impacts. One respondent noted, "I think that having successfully obtained funding, complete[d] the project and published the results were crucial steps in securing respect as a researcher within the institution and relevant to receiving subsequent funding".
The survey results presented by Zed and others ${ }^{1}$ indicate that CSHP members who receive grants believe the CSHP Foundation has a critical role in funding research. Indeed, the Foundation's mission is to "support research and educational programs that advance patient-centred pharmacy practice in hospitals and related health care settings for the betterment of public health". Since it was founded in 1988, the CSHP Foundation has provided this support through grants to CSHP members totalling nearly $\$ 350000$. However, the ability to fund research grants comes primarily from corporate donations (75\%), with donations from individual members and branches (14\%) and the proceeds of fundraising events at CSHP conferences (11\%) accounting for much smaller proportion of available funds.

In 2012, the CSHP Foundation will embark on a promotional and fundraising plan to ensure sustainability and to increase the awards given to members for both research and education projects. The goal is to build a fund of $\$ 1$ million by raising awareness among CSHP members of the value of the grants and their impact on patient care. The plan includes communicating more frequently with CSHP members and potential corporate donors about the value of donating to the CSHP Foundation, increasing administrative support for CSHP Foundation activities, and continuing a direct appeal to distinguished members of the Society such as Past Presidents, Distinguished Service Award recipients, and Fellows.

However, to build a healthy, sustainable organization that is able to provide grants in the future, we also need the support of CSHP members. Such support can be provided by donating through annual appeals or during membership renewal, by volunteering to serve on the Board, or by organizing fundraising events either nationally or at the branch level. The CSHP Research and Education Foundation appreciates all the efforts made by members and corporate sponsors to ensure a vital, sustainable funding body for hospital pharmacy research and education. We would like to extend a special thank-you to the CSHP Research Committee for their diligence in reviewing the annual grant applications and for publishing their evaluation of the research grant program.

\section{Reference}

1. Zed PJ, Ensom MHH, Slavik RS, Wilbur K, Kanji S, Koshman SL, et al. Evaluation of the Research Grant Program of the Foundation of the Canadian Society of Hospital Pharmacists, 1995-2008. Can J Hosp Pharm 2011;64(6):399-404

Kelly Babcock BSP, ACPR, FCSHP (Chair)

Carolyn Bornstein, BScPhm, ACPR, FCSHP, CGP

George De Angelis

Michael Hughes, BSC, BCom, APMR

Heather Neville, BSCPharm, MSC

Glen Pearson, BSc, BSCPhm, PharmD, FCSHP

Myrella Roy, BScPhm, PharmD, FCCP

Terri Schindel, BSCPharm, ACPR, MCE, FCSHP

Marlo Taylor

Board Trustees

CSHP Research and Education Foundation

George De Angelis (AstraZeneca) and Michael Hughes (Sandoz) are the industry representatives on the Board of Trustees of the CSHP Foundation. 